\title{
A inserção de municípios gaúchos no Programa Nacional de Reestruturação e Aparelhagem da Rede Escolar Pública de Educação Infantil (PROINFANCIA) e seus fatores condicionantes ${ }^{1}$
}

\author{
Letícia Maria Schabbach \\ Universidade Federal do Rio Grande do Sul (UFRGS) \\ Marilia Patta Ramos \\ Universidade Federal do Rio Grande do Sul (UFRGS)
}

O estudo examina fatores explicativos da adesão dos municípios gaúchos ao Programa Nacional de Reestruturação e Aparelhagem da Rede Escolar Pública de Educação Infantil (PROINFÂNCIA), instituído pelo Governo Federal em 2007. Por meio de regressão logística envolvendo dados secundários foram testados estatisticamente os seguintes aspectos como explicativos para adesão: a) se o programa está sendo implantado em espaços sociais com maior demanda e menor oferta em educação infantil; b) se as desigualdades municipais pesam na participação (ou não) das prefeituras; c) como a implementação do PROINFANCIA intensifica ou altera as relações entre os entes federados e suas competências no âmbito da educação infantil. Verificou-se que a adesão dos municípios do Rio Grande do Sul ao programa PROINFANCIA e a estratégia federal de indução, no período 2007 a 2009, foram mais efetivas nas prefeituras administradas por partidos de esquerda. Além disto, houve maior adesão dos municípios menos industrializados.

Palavras-chave: educação infantil, política educacional, políticas públicas, implementação, relações intergovernamentais, desigualdade regional

\footnotetext{
${ }^{1} \mathrm{O}$ presente artigo é uma versão adaptada do trabalho publicado no 370 Encontro Anual da ANPOCS, Águas de Lindoia, São Paulo, 23 a 27 de setembro de 2013, disponível em: http://www.anpocs.org/portal/index. php?option=com_docman\&task=doc_view\&gid=8658\&ltemid $=429$
}

[Artigo recebido em 29 de maio de 2015. Aprovado em 23 de agosto de 2016.] 
La inserción de municipios gauchos en el Programa Nacional de Reestructuración y Equipos de la Red Escolar Pública de Educación (PROINFANCIA) y sus factores condicionantes

El estudio examina factores explicativos de la adhesión de los municipios gauchos al Programa Nacional de Reestructuración y Aparejo de la Red Escolar Pública de Educación Infantil PROINFANCIA, instituido por el gobierno federal en 2007. A través de regresión logística que involucró datos secundarios, se probaron estadísticamente los siguientes aspectos como explicativos A) si el programa está siendo implantado en espacios sociales con mayor demanda y menor oferta en educación infantil; B) si las desigualdades municipales pesan en la participación (o no) de las alcaldías; C) cómo la implementación del PROINFANCIA intensifica o altera las relaciones entre los entes federados y sus competencias en el ámbito de la educación infantil. Se verificó que la adhesión de los municipios de Rio Grande do Sul al programa PROINFANCIA y la estrategia federal de inducción, en el período 2007 a 2009, fueron más efectivas en los ayuntamientos administrados por partidos de izquierda. Además, hubo mayor adhesión de los municipios menos industrializados.

Palabras clave: educación infantil, política educativa, políticas públicas, implementación, relaciones intergubernamentales, desigualdad regional

The insertion of gaucho municipalities into the Programa Nacional de Reestruturação e Aparelhagem da Rede Escolar Pública de Educação Infantil (PROINFANCIA) and its conditioning factors

The study verifies the aspects that affect the municipalities in Rio Grande do Sul State adhesion to the National Program for Structuring and Outfit of Public Preschool Network (PROINFANCIA), which was deployed in 2007 and allocates financial assistance to municipalities for the construction and equipping public schools in kindergarten. Through logistic regression involving secondary data, we sought to determine factors associated with municipalities adhesion. The mapping of municipal characteristics that affect the decision to join the PROINFANCIA identified the following respects: a) if the Program was implemented in social spaces with more demand and less supply in early childhood education; b) if the inequality constrainted (or not) the municipality participation; c) as the implementation of PROINFANCIA streamlined relations between federal and competencies within the early childhood education. The results showed the adherence of the municipalities to PROINFANCIA Program were more effective in Municipalities run by leftist parties. In addition, there was a greater participation of the least industrialized cities.

Keywords: education, public policies, implementation, intergovernmental relations, regional inequality 


\section{As políticas educacionais voltadas às crianças de 0 a 5 anos e o PROINFANCIA}

Este estudo procura identificar que características municipais (socioeconômicas, demográficas, situação educacional, capacidade fiscal da prefeitura, investimento municipal em educação geral e infantil, ideologia do partido do prefeito) condicionaram a participação de municípios gaúchos no Programa Nacional de Reestruturação e Aparelhagem da Rede Escolar Pública de Educação Infantil (PROINFANCIA), que destina auxílio financeiro aos municípios para a construção e a equipagem de escolas públicas de educação infantil.

Para tanto, contextualizaremos, inicialmente, a situação das políticas educacionais voltadas ao público infantil menor de sete anos, em que se insere o programa em foco. Em seguida, examinaremos, à luz da literatura sobre políticas públicas, de que forma a implementação de programas federais dinamiza as relações intergovernamentais e quais os prováveis motivos associados à decisão das prefeituras em aderir a políticas formuladas em instâncias superiores de governo. Logo após, são explicitados os procedimentos metodológicos e interpretados os resultados da regressão logística.

É recente no Brasil a inclusão da faixa etária inferior aos sete anos nas políticas educacionais. Pode-se dizer que a partir da Constituição de 1988 garantiu-se o dever do Estado para a educação de crianças de 0 a 6 anos de idade por meio do atendimento em creche e pré-escola.

Ao longo dos últimos 20 anos, a educação infantil passou por forte processo de institucionalização. A promulgação de leis infraconstitucionais, a implantação de programas públicos e a criação de estruturas específicas vêm ampliando a incorporação dessas crianças ao sistema educacional, alterando o caráter assistencialista até então vigente (ROSEMBERG; ARTES, 2012, BARBOSA et al., 2012). Uma das metas previstas nos sucessivos Planos Nacionais de Educação desde 2001 (BRASIL, 2001, 2007), na Emenda Constitucional 59 (BRASIL, 2009), e na Lei no 12.796 (BRASIL, 2013), que oficializou a EC 59, é a universalização do acesso e a ampliação da oferta pública em educação infantil.

Para Barbosa, Gehlen e Fernandes (2012), "Se, inicialmente, o direito à Educação Infantil emergiu atrelado ao direito da família trabalhadora, posteriormente foi constituindo, no contexto social brasileiro, um novo significado e hoje é também reivindicado como um direito social de todas as crianças" (BARBOSA; GEHLEN; FERNANDES, 2012, p. 73). Direito esse pleiteado também pelas trabalhadoras rurais, como aparece, à guisa de exemplo, na pauta da Marcha das Margaridas de 2011, segundo informação de Rosemberg e Artes (2012). Tal reinvindicação provavelmente esteja associada às mudanças nas relações familiares e à crescente participação da mulher no trabalho e na vida social dos espaços rurais (BARBOSA; Gehlen; Fernandes, 2012). 
Em consonância com as normas legais que foram instauradas após a Constituição de 1988, a atenção às crianças pequenas tem sido incorporada por vários programas educacionais (SAVIANI, 2007), exigindo uma adequação ou aprimoramento desses para a faixa etária de até cinco anos de idade, por exemplo: no transporte escolar, a adequação dos assentos e da segurança nos veículos; nos programas de livros didáticos, a literatura infantil voltada àquele período etário; nas ações de formação pedagógica, a capacitação específica dos professores da educação infantil; a alimentação escolar para creches e pré-escolas, bem como a observância de infraestrutura apropriada. Além disto, a exigência de padrões mínimos de qualidade em termos de infraestrutura tornou-se um aspecto central das ações do Ministério da Educação (MEC), desde 1998.

Segundo Barbosa, Gehlen e Fernandes (2012), tais iniciativas trouxeram avanços quanto ao provimento da educação infantil no País: expansão do atendimento das crianças de 0 a 5 anos, exigência de qualificação dos profissionais que trabalham diretamente com elas, oferta de programas específicos para construção, reforma e aparelhamento de escolas infantis, para citar alguns avanços. Contudo, ainda persiste uma defasagem quanto à participação da educação infantil em relação aos outros níveis de ensino, por exemplo, o investimento público direto nessa etapa de ensino atingiu, em $2011,8,7 \%$, percentual bastante inferior aos $29,8 \%$ da 1 a a 4 a séries; $27,8 \%$

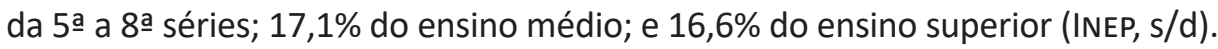

Ademais, a cobertura em termos de oferta em educação infantil é ainda reduzida em comparação com as outras etapas de ensino. Considerando-se dados calculados pelo Instituto de Pesquisa Econômica Aplicada (IPEA) sobre frequência líquida (percentual da população por faixa etária que frequenta escola de acordo com o nível de ensino da matrícula) no período 2001 a 2009, constata-se que, enquanto a frequência líquida dos 4 a 6 anos aproximou-se dos $60 \%$ ao longo da série histórica, a dos 0 a 3 anos passou de 10\% em 2001 para 18,4\% em 2009, aumentando 84\% (IPEA, 2011, p. 143). Entretanto, essa faixa etária apresentou os menores percentuais de atendimento entre todas as etapas da educação básica.

Por outro lado, é desigual o acesso das crianças com cinco anos ou menos à escola, fazendo com que parcela considerável da população brasileira ainda não tenha esse direito assegurado: as crianças de 0 a 3 anos, as de famílias de renda baixa, e as residentes em áreas rurais, comunidades quilombolas e indígenas ou em assentamentos agrícolas². Por vezes, os limites etários normatizados (creche - de 0 a 3 anos e 11 meses; pré-escola - de 4 a 5 anos e 11 meses, conforme a Lei de Diretrizes

\footnotetext{
${ }^{2}$ Além da menor oferta, as crianças de 0 a 3 anos - principalmente as do meio rural - são matriculadas em escolas precárias quanto aos espaços, equipamentos e materiais pedagógicos, de acordo com a Pesquisa Nacional "Caracterização das práticas educativas com crianças de 0 a 6 anos residentes em áreas rurais" (BARBOSA et al., 2012), realizada em 2012 através de convênio entre o MEC e a UFRGS.
} 
e Bases/1996) não são respeitados, fazendo com que existam "crianças fora de lugar" (ROSEMBERG; ARTES, 2012) nas instituições de ensino: crianças muito pequenas sendo atendidas em pré-escolas, crianças de quatro ou mais anos sendo acolhidas em creches, crianças de 0 a 5 anos incluídas em turmas multi-etapas ou do ensino fundamental, crianças residentes em áreas rurais frequentando escolas urbanas.

O Gráfico 1, a seguir, mostra os percentuais de atendimento de crianças ${ }^{3}$ entre 0 e 6 anos (sem considerar a etapa de ensino), no ano de 2010 no Brasil. Verifica-se que os maiores percentuais de matriculados são encontrados entre as crianças de seis anos de idade (94\%), sem variações significativas em termos de local de residência do aluno (se área urbana ou rural). Provavelmente, a maioria dessas crianças frequentou, naquele ano, o ensino fundamental, mais próximo da universalização. Para crianças de quatro e cinco anos, o percentual de atendimento atingiu $68 \%$. Nessa faixa etária, há maior incidência relativa de matriculados da área urbana do que da área rural, diferença que atinge 19 pontos percentuais. Já entre os de 0 a 3 anos de idade, o índice de atendimento é bastante reduzido, de 14\%, repetindo-se nesse intervalo etário o maior acesso dos matriculados residentes em área urbana, que superamos da zona rural em dez pontos percentuais.

Gráfico 1- Percentuais de matriculados conforme a faixa etária, Brasil, 2010.

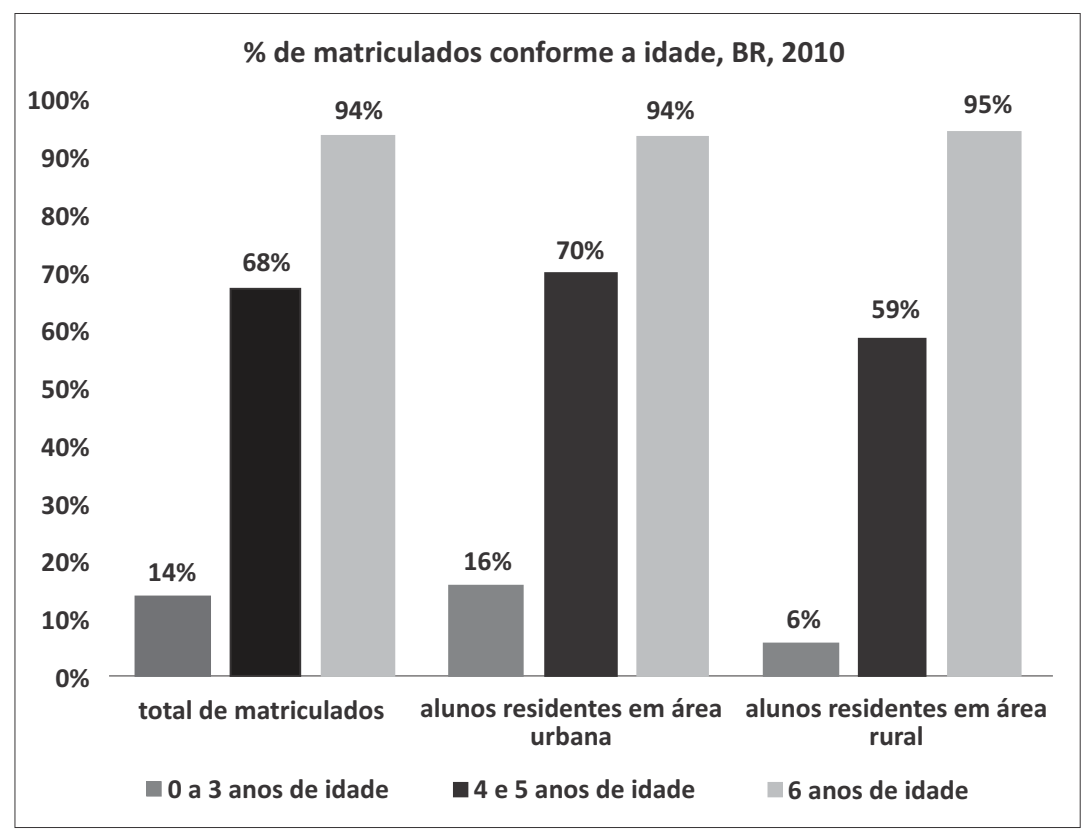

Fonte: INEP. Censo Escolar 2010 - Microdados. Elaboração pelas autoras.

\footnotetext{
${ }^{3}$ Os percentuais dos gráficos 1 e 2 referem-se à proporção de matriculados em relação à população na respectiva faixa etária.
} 
Percebe-se que a meta (a ser atingida até o ano de 2016) de universalização do atendimento de quatro e cinco anos e de cobrir, no mínimo, 50\% da demanda existente dos 0 aos 3 anos, conforme previsto na Lei 12.796/2013 (a norma mais recente), está longe de ser alcançada a curto prazo.

Podemos acreditar que, em meio a essa situação, a obrigatoriedade legal de ampliação da oferta de vagas para crianças de 0 a 5 anos, recentemente regulamentada, tornou-se um forte elemento indutor da busca por recursos federais pelas prefeituras municipais, em especial daquelas sem disponibilidade de recursos fiscais.

Nesse contexto, é promulgado, em 2007, o PROINFANCIA ${ }^{4}$, programa por meio do qual o Governo Federal destina recursos financeiros às prefeituras municipais (e ao Distrito Federal) para a construção, reforma e aquisição de equipamentos e mobiliário para creches e pré-escolas públicas ${ }^{5}$. Tendo como público-alvo as crianças de 0 a 5 anos de idade, ele foi instituído pela Resolução no 06, de 24 de abril de 2007, do Conselho Deliberativo do Fundo Nacional de Desenvolvimento da Educação (FNDE). O FNDE é o órgão técnico do Ministério da Educação (MEC) que acompanha o processo de contratação e libera os recursos aos municípios.

Dentro do programa existem dois tipos de projetos arquitetônicos para a construção das escolas: o projeto B (com capacidade para 240 crianças em dois turnos, contando com 8 salas pedagógicas, sala de informática, cozinha, refeitório, pátio coberto, entre outros ambientes), e o projeto C (com capacidade para 120 crianças em dois turnos, com 4 salas pedagógicas e demais espaços previstos no projeto $B)^{6}$. Os modelos são os mesmos para todo o País, mas os municípios podem solicitar alterações quando estiverem planejando a construção.

Para se inserirem no PROINFANCIA, as prefeituras devem elaborar o Plano de Ações Articuladas (PAR) para construção de escolas de educação infantil e assinar o Termo de Adesão ao programa. Dentre os critérios para a concessão da assistência financeira, conforme consta no artigo 3ํ da Resolução que cria o PROINFANCIA (BRASIL, 2007), destacam-se:

- Observância dos Parâmetros Básicos de Infraestrutura para Instituições de Educação Infantil.

\footnotetext{
${ }^{4}$ As informações sobre o PROINFANCIA foram obtidas em: Brasil (2007); BLog do PLANALTo (2011); ALmeIDA (2011); MEC MUdA CRITÉRIOS... (2011); e nos portais do MEC (http://portal.mec.gov.br), do FNDE (http://www. fnde.gov.br/fnde/institucional) e do SIMEC (http://painel.mec.gov.br).

${ }^{5}$ O programa prevê, ainda, capacitação dos gestores e professores sobre a temática da educação infantil e sobre a metodologia de elaboração de projetos.

6 Existe ainda o modelo A, de responsabilidade precípua das Prefeituras Municipais.
} 
- No caso de construção, concordância do proponente em adotar o projeto executivo disponibilizado pelo FNDE.

- Aprovação de Plano de Trabalho pela Diretoria de Programas e Projetos Educacionais (DIRPE/FNDE).

- No caso de construção ou reforma, apresentação de documentos comprobatórios da propriedade do terreno, o qual deve ter área compatível com o projeto solicitado.

- Demanda mínima de crianças não matriculadas (120 ou 240, conforme o censo escolar mais recente).

Além do projeto de implantação, o município é responsável pela licitação da obra e pelo monitoramento da construção, devendo publicar as informações no Sistema Integrado de Planejamento, Orçamento e Finanças do Ministério da Educação (SIMEC).

A solicitação é feita diretamente ao MEC no PAR e os documentos são enviados eletronicamente via SIMEC. Se aprovada, a transferência de recursos é efetuada por meio de repasse automático ou da celebração de convênio entre o FNDE e o município solicitante, o qual se compromete com a assunção de cerca de $1 \%$ do valor total da obra, enquanto contrapartida.

Em 2011 o PROINFANCIA foi inserido na segunda etapa do Programa de Aceleração do Crescimento (PAC2), em uma tentativa do Governo Federal de agilizar a execução das obras e a própria consolidação do programa. Nessa nova etapa, a adesão do município passou a ser formalizada através de termo de compromisso, sem a exigência de convênio (que era obrigatório até 2010), o que facilitou a liberação e a transferência dos recursos. Até 2014, o PAC2 previa a distribuição de $\mathrm{R}$ \$, 6 bilhões para a criação de cerca de 1,5 milhões de vagas em 6 mil unidades de educação infantil.

Ainda de acordo com informações do SIMEC, entre 2007 e 2011 municípios de todos os estados brasileiros já haviam sido contemplados pelo PROINFANCIA, sendo que em seis estados mais da metade das prefeituras receberam recursos para a construção de escolas infantis: Mato Grosso do Sul (75 municípios, 96\% do total de municípios do estado), Tocantins (91 municípios, 65\%), Ceará (106 municípios, 58\%), Mato Grosso (79 municípios, 56\%), Rio Grande do Sul (261 municípios, 53\%) e Rio Grande do Norte (86 municípios, 51\%).

Verifica-se, pelo exposto acima, que o PROINFANCIA tornou-se um programa federal abrangente e estratégico diante da baixa oferta de educação infantil nos municípios brasileiros. As novas exigências legais acerca da ampliação do provimento de vagas em creches e pré-escolas certamente fizeram com que mais e mais municípios recorressem aos recursos do programa, especialmente a partir de 2010, após a promulgação da EC no 59. 
Representando um programa federal cuja execução fica a cargo dos municípios, o PROINFANCIA dinamizou as relações entre os entes federados no âmbito das políticas educacionais brasileiras.

\section{Fundamentação teórica}

Paul Berman (2007) argumenta que o estudo do processo de implementação de políticas públicas deve considerar o contexto institucional específico de cada área, por exemplo, a educação. Conforme o autor, um setor de política é composto por diferentes organizações, atores, dinâmicas, regras e padrões de comportamento que configuram uma macroestrutura debilmente integrada. Procurando dar conta de tal complexidade, ele propõe o conceito de "Macro implementação", que compreende todo o setor da política, desde os níveis federais até os locais, onde a implementação ocorre ao longo de uma série de transições, entre as quais: 1a transição - da decisão política ao programa de governo; 2 2 - do programa de governo à adoção de um projeto local; 3a - da adoção do projeto às práticas operacionalizadas localmente; 4a - dessas aos resultados locais.

O foco deste estudo insere-se na segunda transição, qual seja: existindo o programa governamental, esse conduziria à adoção de um projeto local. Entretanto, a simples adoção (ou adesão) não garante o êxito da política, pois devem ser levadas em conta as práticas concretas adotadas pelas organizações e os resultados produzidos localmente, no âmbito da "micro implementação" (BERMAN, 2007), cuja análise foge aos objetivos do presente trabalho.

Por outro lado, da literatura brasileira na área da policy analysis tem-se que a produção de programas públicos acontece nos marcos de um desenho institucional federalista7, que condiciona as decisões dos atores governamentais (SoUZA, 2005; Arretche, 2005; Almeida, 2005; Abrucio; Franzese, 2011). Segundo Souza (2005), o federalismo brasileiro é tríplice, reunindo União, estados e municípios, tendo iniciado com a proclamação da República e regulamentado pela primeira vez na Constituição de 1891.

Federalismo não se confunde com descentralização, que se refere à "transferência de autoridade e responsabilidade, no que diz respeito a funções públicas do governo central para governos locais ou intermediários, para organizações governamentais semi-independentes e/ou para o setor privado" (ALMEIDA, 2005, p. 30).

Utilizando a tipologia proposta por Souza (2005), podemos destacar duas formas principais que caracterizam os processos de descentralização de políticas públicas

\footnotetext{
7 Para Rodden (2005, p. 17), federalismo significa que "para algum subconjunto das decisões ou atividades do governo central torna-se necessário obter o consentimento ou a cooperação ativa das unidades subnacionais."
} 
no País: por um lado, a realocação, modalidade na qual os entes subnacionais têm maior capacidade de captação de recursos e decisão sobre políticas e, portanto, maior autonomia. Por outro, na consolidação as responsabilidades pela implementação e gestão de políticas previamente definidas pela União são transferidas para estados e municípios, reservando-Ihes menor autonomia e poder de decisão sobre os conteúdos e as metas das ações públicas. Nesse sentido, a produção de políticas públicas no território brasileiro ocorre dentro de um continuum entre realocação e consolidação, dentro do qual os governos municipais (e estaduais) oscilam entre um maior ou menor poder de decisão e autonomia sobre as políticas formuladas em nível federal.

Ao analisar a nossa história republicana a partir das constituições federais, Souza (2005) identificou oscilações entre tendências e mecanismos mais ou menos descentralizadores, que ora limitavam ora expandiam a autonomia federal, configurando um processo que Almeida (2005) caracterizou como "longo e espasmódico".

Nessa trajetória, os ritmos e formatos dos processos descentralizadores foram condicionados pelo desenho de cada política e pela distribuição prévia de competências e recursos entre os entes federados, como salientam Almeida (2005) e Souza (2005). Existe uma série de áreas de políticas sociais que é de competência partilhada entre os três níveis de governo, entre elas a cultura, a educação e a ciência (SoUzA, 2005). No âmbito do ensino fundamental e infantil, a partir da segunda metade da década de 1990 (com a promulgação da LDB em 1996 e a implantação do Fundo de Manutenção e Desenvolvimento do Ensino Fundamental - FUNDEF em 1997), os governos municipais passaram a ser provedores importantes desse nível educacional, acessando recursos federais provenientes de programas os quais, ao mesmo tempo em que concediam benefícios, estipulavam sanções aos governos subnacionais (SOUZA, 2005; ALMEIDA, 2005). Até então, a competência principal no ensino fundamental era dos governos estaduais.

Melo (1996) e Arretche (2005) atribuem ao nosso federalismo um caráter mais competitivo e conflitivo do que cooperativo. Isso se deve às desigualdades entre os governos subnacionais para implementarem políticas públicas, especialmente quanto às suas capacidades institucionais (financeiras, técnicas e de gestão), bem como à inexistência de mecanismos de coordenação que estimulem a cooperação intergovernamental, tanto vertical quanto horizontal (SOUZA, 2005; ABRÚcio; FRANZESE, 2011).

Embora não exista legislação específica que prescreva normas de cooperação entre União e entes federados, tais relações ocorrem na prática: "Os governos subnacionais partilham recursos federais, os municípios partilham parcelas de 
impostos estaduais e existem várias políticas sociais, particularmente saúde e educação fundamental, que contam com diretrizes e recursos federais, mas são implementadas principalmente pelos municípios" (SOUZA, 2005, p. 114).

Em adendo, existem formas recentes de cooperação intergovernamental, como, por exemplo: as coordenações regionais e os consórcios horizontais e interníveis (consórcios municipais e intermunicipais, espécie de "associativismo territorial", no dizer de Abrúcio e Franzese, [2011]); e os convênios entre entes federados, que visam promover a mútua colaboração entre os partícipes a fim de atingirem objetivos institucionais comuns. Esses últimos podem assumir várias formas, como "repasse de verbas, uso de equipamentos, de recursos humanos e materiais, de imóveis, de know how [...]" (ABRúcIO; FrANZESE, 2011, p. 15). Os repasses são liberados após o envio e a aprovação dos projetos estaduais ou municipais, nos quais é exigido o alinhamento do objeto e plano de trabalho à execução financeira (IPEA, 2011).

Em geral, os convênios inserem-se na categoria "transferências voluntárias" não condicionadas ${ }^{8}$ (as quais também abrangem acordos, ajustes ou outros instrumentos similares) do Governo Federal para os outros níveis governamentais (estados, municípios, Distrito Federal), a título de cooperação, auxílio ou assistência financeira. Esse era o formato do PROINFANCIA até 2011; com o PAC2 a participação dos municípios passou a ser formalizada por meio de termo de compromisso.

Ao estudarem os acordos realizados na forma de convênios entre a União e os governos subnacionais, Abrúcio e Franzese (2011) verificaram que os termos são invariavelmente definidos pela esfera superior de governo, assemelhando-se mais a uma adesão por uma das partes, do que a uma negociação com liberdade de decisão. Nesse mesmo sentido, o IPEA (2011) menciona o restritivo "contrato de adesão" dos governos subnacionais para com a União, com o intuito de receberem transferências voluntárias.

Com efeito, as transferências voluntárias da União dificilmente escapam ao padrão de atendimento a ações previamente delineadas pelo próprio governo federal, por meio dos programas que ele elabora e anuncia e aos quais os estados, o DF e os municípios aderem ou não - e quase sempre o fazem, pois costumam necessitar dos recursos. Se, por um lado, essa configuração institucional restringe o regime de colaboração a praticamente um "contrato de adesão", por outro, facilita o acesso a recursos federais, até mesmo por parte de UFs, que, de outra maneira, e até por conta de sua reduzida capacidade de gestão e de captação de recursos, pouco sucesso teriam em tal empreitada (IPEA, 2011, p. 140).

\footnotetext{
${ }^{8}$ As transferências voluntárias e os convênios são monitorados pelo Sistema Integrado de Administração Financeira do Governo Federal (SIAFI), e podem ser consultados no portal da transparência nos recursos públicos federais: http://www.portaldatransparencia.gov.br/.
} 
Em suma, o que se observa desde a década de 2000 no País, é que a implementação de programas federais tem progressivamente se caracterizado pela negociação direta entre União e governos municipais, tornando-os responsáveis pela provisão e execução da maioria dos serviços públicos e das políticas sociais em seus territórios.

Entre as formas pelas quais os entes federados assumem a gestão de políticas públicas, pode-se citar: por iniciativa própria, por adesão a algum programa proposto por outro nível governamental mais abrangente e/ou por imposição legal. Mas o que levaria os municípios a aderirem a políticas formuladas por outra esfera governamental?

No processo de tomada de decisão em torno da adesão a programas federais, e ao cotejar as suas vantagens e desvantagens, supõe-se que os municípios considerem a disponibilidade de recursos fiscais e administrativos próprios, a existência (ou não) de ações similares que consolidaram estruturas e conhecimento acumulado sobre determinada área de política (ou seja, o efeito de feedback das políticas prévias), bem como a existência de indicadores que sinalizem a magnitude do problema.

Portanto, as variáveis municipais são levadas em conta na decisão sobre a participação em programas federais, como salientam autores do campo das políticas públicas.

Por exemplo, Berman (2007), ao citar estudos sobre a adoção de políticas federais por prestadores locais, ressalta que tal adoção depende: do tipo de programa e dos incentivos oferecidos aos executores, das características do público alvo, das condições econômicas, sociais e políticas do contexto mais geral e local, bem como do grau de consonância entre os interesses locais e os objetivos programáticos federais. Por sua vez, Arretche e Marques (2002), em estudo sobre os condicionantes locais da descentralização das políticas de saúde, concluíram que as transferências federais não reduziram as desigualdades municipais quanto ao acesso a serviços públicos de saúde, pois as regras que as que orientaram visavam mais à consolidação da própria descentralização do que à redução das diferenças entre os municípios. Nesse sentido, as desigualdades entre os municípios influenciam a sua adesão (ou não) aos programas formulados em nível superior de governo, mas os resultados desses nem sempre impactam na redução dessas mesmas disparidades.

Além disso, os níveis superiores de governo elaboram estratégias de indução (através das prescrições legais, incentivos financeiros e assistência técnica) para assegurar a adesão dos governos locais, as quais são consideradas por Arretche (1999) e Souza (2004) um fator fundamental para eles assumirem a provisão e a gestão de serviços sociais. Em síntese, 
Considerando um leque possível de áreas de aplicação de recursos, esta decisão será o resultado de um cálculo no qual a natureza da política, o legado das políticas prévias, as regras constitucionais e a existência de uma estratégia eficientemente desenhada e implementada por parte de um nível de governo mais abrangente são componentes decisivos. (ARRETCHE, 1999, p. 119-120, grifos nossos)

Os aspectos acima referenciados são importantes para se analisar os motivos que levaram os municípios a aderirem (ou não) ao Programa Nacional de Reestruturação e Aparelhagem da Rede Escolar Pública de Educação Infantil. Tendo como universo empírico os municípios do Rio Grande do Sul, a seguir analisaremos os fatores que condicionaram a sua inserção (ou não) no PROINFANCIA.

\section{Materiais e Métodos}

A fim de examinarmos os fatores condicionantes da adesão dos municípios sul-rio-grandenses ao Programa PROINFANCIA, construiu-se uma base de dados com variáveis para o conjunto dos municípios do estado (496, conforme o Censo Demográfico de 2010).

A opção pela análise de regressão logística decorre do fato de que ela é usada quando a variável dependente é dicotômica, assumindo dois valores: 1 referente à ocorrência do fenômeno investigado (na nossa pesquisa: aderiu ao PROINFANCIA), 0 sinalizando a não ocorrência (não aderiu ao PROINFANCIA). Essa análise possibilita aquilatar as razões das chances ${ }^{9}$ de municípios que possuem certas características (representadas pelas variáveis independentes) terem aderido ao programa, em comparação com os que não o fizeram. $E$, ainda, quais aspectos reduzem a chance de adesão ${ }^{10}$. O modelo foi estimado através do software SPSS .

\section{Operacionalização das variáveis dependente e independentes}

a) Variável dependente: adesão ao PROINFANCIA, aqui considerada como a data de protocolo do processo no FNDE ou de início da vigência do convênio firmado entre o Governo Federal e a prefeitura municipal.

É uma variável dicotômica, em que o valor 1 indica que o município aderiu e 0 que não aderiu ao PRONFANCIA, no período 2007 a 2009, momento anterior à implantação da EC 59, ato que estipulou metas obrigatórias de ampliação de

\footnotetext{
${ }^{9}$ Estatisticamente a chance de aderir seria a razão entre a probabilidade de aderir e a de não aderir. Já a chance de não aderir seria a razão entre a probabilidade de não aderir e a de aderir. A razão das chances seria a divisão entre a chance de aderir sobre a chance de não aderir.

${ }^{10}$ Para maiores detalhes sobre a regressão logística, consultar: Powers (2000) e Long e Freese (2006).
} 
vagas em educação infantil, representando uma forte indução para os governos municipais buscarem recursos federais.

$\mathrm{Na}$ construção da variável dependente foi necessário identificar o ano em que os municípios encaminharam suas propostas e projetos ao MEC/FNDE, o que foi possível através da consulta a sites e documentos do Ministério da Educação, resultando na distribuição mostrada na tabela seguinte.

Examinando-se a tabela 1, verifica-se que, em dezembro de 2014 (data de corte da pesquisa), 336 municípios gaúchos dos 467 considerados estavam inseridos no PROINFANCIA, ou seja, $72 \%$ do total do estado. Desses, 160 municípios (48\% dos que aderiram) encaminharam solicitação ou firmaram convênio no período 2007 a 2009, ao passo que 52\% o fez entre os anos 2010 e 2014.

Tabela 1 - Distribuição dos municípios do Rio Grande do Sul conforme adesão ao PROINFANCIA, 2007-2014

\begin{tabular}{c|c|c}
\hline Período & Número de municípios & $\begin{array}{c}\text { \% dos que } \\
\text { aderiram }\end{array}$ \\
\hline 2007a 2009 & 160 & $48 \%$ \\
\hline 2010 a 2014 & 176 & $52 \%$ \\
\hline Não aderiram até o final de 2012 & $\begin{array}{l}\text { 131(28\% do total de } \\
\text { municípios gaúchos) }\end{array}$ & NA \\
\hline Total & 467 & - \\
\hline
\end{tabular}

Fontes: Ministério da Educação. Elaboração pelas autoras.

b) Variáveis independentes

Os indicadores (e suas respectivas variáveis) aqui considerados como "fatores condicionantes da adesão ao PROINFANCIA", referem-se a características socioeconômicas e demográficas, político-ideológicas, de oferta de educação geral e infantil, de capacidade fiscal da prefeitura, e de existência de estruturas públicas municipais prévias no tocante à educação em geral e infantil. As informações são de anos anteriores ao início da vigência do programa (2007), pois, para inferirmos causalidade as variáveis independentes devem ter sido medidas em momento anterior à dependente.

A bateria inicial de variáveis independentes foi submetida a um exame de multicolinearidade, onde se consideraram altamente correlacionadas as duplas que tiveram coeficientes de correlação iguais ou acima de 0,8. A partir daí, uma das variáveis colineares foi excluída, restando 47 variáveis agrupadas em 10 indicadores, que constam no Quadro 1, a seguir. As variáveis destacadas com um asterisco foram as selecionadas a partir do teste de multicolinearidade. 


\section{Quadro 1 - Indicadores e variáveis independentes}

\begin{tabular}{|c|c|c|}
\hline Indicador & $\begin{array}{l}\text { № } \\
\text { Variável }\end{array}$ & Descrição das variáveis independentes \\
\hline \multirow{6}{*}{ Aspectos demográficos } & V01 & População de 0 a 5 anos de idade $-2000^{*}$ \\
\hline & V02 & $\begin{array}{l}\% \text { da faixa etária de } 0 \text { a } 5 \text { anos sobre a população } \\
\text { total - 2000* }\end{array}$ \\
\hline & V03 & $\begin{array}{l}\text { \% da população rural de } 0 \text { a } 5 \text { anos sobre a popu- } \\
\text { lação de } 0 \text { a } 5 \text { anos - 2000* }\end{array}$ \\
\hline & V04 & Variação populacional no período 2000 a 2007 \\
\hline & V05 & Taxa de urbanização - 2000 \\
\hline & V06 & Densidade demográfica 2000 - habitantes por km² \\
\hline \multirow{2}{*}{$\begin{array}{l}\text { Pertencimento à RMPA ou } \\
\text { com influência externa }\end{array}$} & V07 & $\begin{array}{l}\text { Pertencimento à Região Metropolitana de Porto } \\
\text { Alegre- } 2006 \text { (dicot.,1 = RMPA) }\end{array}$ \\
\hline & V08 & $\begin{array}{l}\text { Influência externa (municípios com influência além } \\
\text { da local) (dicot., } 1 \text { = influente) }\end{array}$ \\
\hline \multirow{5}{*}{$\begin{array}{l}\text { Atividades econômicas } \\
\text { principais }\end{array}$} & V09 & $\begin{array}{l}\% \text { do valor adicionado }{ }^{a} \text { proveniente da indústria } \\
\text { - } 2006\end{array}$ \\
\hline & V10 & $\begin{array}{l}\text { \% de ocupados na indústria de transformação } \\
\text { - } 2000\end{array}$ \\
\hline & V11 & $\begin{array}{l}\text { \% do valor adicionado proveniente dos serviços } \\
\text { - } 2006\end{array}$ \\
\hline & V12 & $\begin{array}{l}\% \text { de ocupados no comércio e reparação de } \\
\text { veículos- } 2000^{*}\end{array}$ \\
\hline & V13 & $\begin{array}{l}\% \text { da área ocupada por estabelecimentos de } \\
\text { agricultura familiar }-2006^{b *}\end{array}$ \\
\hline \multirow{4}{*}{ Riqueza e origem da renda } & V14 & Produto interno bruto per capita - 2006 \\
\hline & V15 & Renda per capita- 2000* \\
\hline & V16 & $\begin{array}{l}\text { Participação percentual das rendas do trabalho } \\
\text { - } 2000\end{array}$ \\
\hline & V17 & $\begin{array}{l}\text { Participação percentual das rendas de } \\
\text { transferências governamentais } 2000^{c}\end{array}$ \\
\hline \multirow{4}{*}{$\begin{array}{l}\text { Qualidade de vida inclusive } \\
\text { educação }\end{array}$} & V18 & $\begin{array}{l}\text { Índice de desenvolvimento socioeconômico } \\
-2006^{d}\end{array}$ \\
\hline & V19 & $\%$ de domicílios adequadose- 2000 \\
\hline & V20 & $\begin{array}{l}\text { Taxa de alfabetização das pessoas com } 15 \text { ou mais } \\
\text { anos - } 2000\end{array}$ \\
\hline & V21 & IDEB do 4 ou 50 ano $-2005^{f}$ \\
\hline
\end{tabular}




\begin{tabular}{|c|c|c|c|}
\hline \multicolumn{2}{|l|}{ Indicador } & $\begin{array}{l}\text { № } \\
\text { Variável }\end{array}$ & Variáveis Independentes \\
\hline \multirow{4}{*}{\multicolumn{2}{|c|}{ Vulnerabilidade social }} & V22 & $\begin{array}{l}\text { \% de pessoas de } 0 \text { a } 14 \text { anos com renda } \\
\text { domiciliar per capita inferior à } R \$ 37,75- \\
\text { indigentes } 2000^{*}\end{array}$ \\
\hline & & V23 & $\begin{array}{l}\text { \% de crianças de } 0 \text { a } 6 \text { anos que residem em } \\
\text { domicílios inadequados }-2000\end{array}$ \\
\hline & & V24 & $\begin{array}{l}\text { Mortalidade infantil (óbitos até } 1 \text { ano/nascidos } \\
\text { vivos x 1000) - } 2006\end{array}$ \\
\hline & & V25 & \% chefes de domicílio sem instrução - 2000 \\
\hline \multirow{2}{*}{\multicolumn{2}{|c|}{ Capacidade fiscal da prefeiturah }} & V26 & $\begin{array}{l}\text { Capacidade de gasto municipal (receitas } \\
\text { correntes - despesas com transferência de } \\
\text { capital } 2006 \text { / pop 2000), em reais }\end{array}$ \\
\hline & & V27 & $\begin{array}{l}\% \text { receita tributária sobre receitas correntes } \\
-2006\end{array}$ \\
\hline \multirow{9}{*}{$\begin{array}{l}\text { Oferta } \\
\text { educacional do } \\
\text { município - em } \\
\text { geral e educação } \\
\text { infantil (pública e } \\
\text { privada) }\end{array}$} & $\begin{array}{l}\text { Educação } \\
\text { Geral }\end{array}$ & V28 & Número de habitantes por escola* \\
\hline & \multirow{8}{*}{ Ed Infantil } & V29 & $\begin{array}{l}\% \text { de crianças de } 0 \text { a } 5 \text { anos que frequentaram } \\
\text { escola (IBGE) / população de } 0 \text { a } 5 \text { anos } \\
\text { - 2000* }\end{array}$ \\
\hline & & V30 & $\begin{array}{l}\text { \% de crianças de } 0 \text { a } 5 \text { anos matriculadas em } \\
\text { creche ou pré-escola em } 2006 \text { (Censo Escolar) } \\
\text { sobre a população nesta faixa etária, em2000 }\end{array}$ \\
\hline & & V31 & $\begin{array}{l}\% \text { de professores da educação infantil sobre o } \\
\text { total de professores - } 2006\end{array}$ \\
\hline & & V32 & $\begin{array}{l}\text { \% das escolas localizadas na área rural que } \\
\text { oferecem educação infantil (EI) e outros níveis } \\
\text { de sobre o total de escolas que oferecem El e } \\
\text { outros níveis de ensino - 2006* }\end{array}$ \\
\hline & & V33 & $\begin{array}{l}\text { \% de alunos de creche e pré-escola que } \\
\text { utilizam transporte escolar público- } 2006\end{array}$ \\
\hline & & V34 & $\begin{array}{l}\% \text { das escolinhas' sobre o total de escolas que } \\
\text { oferecem El - 2006* }\end{array}$ \\
\hline & & V35 & $\begin{array}{l}\% \text { das escolinhas localizadas na área rural sobre } \\
\text { o total de escolinhas - } 2006\end{array}$ \\
\hline & & V36 & $\begin{array}{l}\% \text { de escolinhas particulares sobre o total de } \\
\text { escolinhas - } 2006\end{array}$ \\
\hline
\end{tabular}




\begin{tabular}{|c|c|c|c|}
\hline \multirow{9}{*}{$\begin{array}{l}\text { Estruturas } \\
\text { municipais e } \\
\text { investimento da } \\
\text { prefeitura em } \\
\text { educação-em } \\
\text { geral e educação } \\
\text { infantil }\end{array}$} & \multirow{6}{*}{$\begin{array}{l}\text { Educação } \\
\text { Geral }\end{array}$} & V37 & $\begin{array}{l}\text { Existência de Sistema Municipal de Ensino - } \\
2006 \text { (dicotômica, } 1 \text { = existe) }\end{array}$ \\
\hline & & V38 & $\begin{array}{l}\text { Existência de Plano Municipal de Educação - } \\
2006 \text { (dicotômica) }\end{array}$ \\
\hline & & V39 & $\begin{array}{l}\text { Existência de Fundo Municipal de Educação - } \\
2006 \text { (dicotômica) }\end{array}$ \\
\hline & & V40 & $\begin{array}{l}\text { Existência de Conselho Municipal de Educação } \\
-2006 \text { (dicotômica) }\end{array}$ \\
\hline & & V41 & $\begin{array}{l}\text { Taxa das despesas pagas em educação 2006/ } \\
\text { população } 2000\end{array}$ \\
\hline & & V42 & $\begin{array}{l}\% \text { das escolas municipais sobre o total de } \\
\text { escolas - } 2006\end{array}$ \\
\hline & \multirow{3}{*}{$\begin{array}{l}\text { Educação } \\
\text { Infantil }\end{array}$} & V43 & $\begin{array}{l}\text { \% das despesas com educação infantil nas } \\
\text { despesas pagas em educação - } 2006\end{array}$ \\
\hline & & V44 & $\begin{array}{l}\text { \% das escolas municipais que oferecem com El } \\
\text { (escolinhas ou outras) sobre o total de escolas } \\
\text { que oferecem educação infantil- } 2006^{*}\end{array}$ \\
\hline & & V45 & $\begin{array}{l}\% \text { das escolinhas municipais sobre o total de } \\
\text { escolinhas - } 2006\end{array}$ \\
\hline \multirow{2}{*}{\multicolumn{2}{|c|}{ Ideologia do partido do prefeito }} & V46 & $\begin{array}{l}\text { Ideologia do partido do prefeito na gestão } \\
2005-2008 \text { (dicotômica, } 1=\text { esquerda)' }\end{array}$ \\
\hline & & V47 & $\begin{array}{l}\text { Ideologia do partido do prefeito na gestão } \\
2009-2012 \text { (dicotômica) }\end{array}$ \\
\hline
\end{tabular}

Fonte: Cálculo das variáveis e elaboração do quadro pelas autoras, a partir de diversas fontes.

a $\mathrm{O}$ valor adicionado é aquele que a atividade agrega aos bens e serviços consumidos no seu processo produtivo.

${ }^{\mathrm{b}}$ Agricultores ou empreendedores familiares, conforme a Lei no 11.326/2006, abrangem aqueles: cuja área tenha até 4 módulos fiscais, utilizem predominantemente mão de obra familiar, tenham percentual mínimo da renda familiar oriundo de seu próprio estabelecimento, dirijam o seu estabelecimento com a família, integrem as populações do campo. A variável refere-se ao percentual da área total dos estabelecimentos agropecuários ocupados pela agricultura familiar em determinado município, sendo a proporção restante ocupada pela agricultura não familiar. ' Equivale à participação das rendas de transferências governamentais (aposentadorias, pensões e programas oficiais de auxílio, como renda mínima, bolsa-escola e seguro-desemprego, etc.) na renda total do município.

d O Índice de Desenvolvimento Socioeconômico (IDESE) dos municípios do RS é um índice sintético inspirado no Índice de Desenvolvimento Humano, que abrange quatro blocos de indicadores: educação, renda, saneamento e saúde.

e Para o IBGE, a categoria adequada refere-se aos domicílios particulares permanentes com rede geral de água, rede geral de esgoto ou fossa séptica, coleta de lixo por serviço de limpeza e até 2 moradores por dormitório.

${ }^{f} \mathrm{O}$ Índice de Desenvolvimento da Educação Básica (IDEB) é um indicador de qualidade educacional que combina informações de desempenho em exames padronizados (Prova Brasil ou Saeb) - obtido pelos estudantes ao final das etapas de ensino (4a e 8aำa séries do ensino fundamental e 3a série do ensino médio) - com informações sobre rendimento escolar (aprovação). Tem periodicidade anual e as unidades de investigação são as próprias escolas. Embora o índice não avalie diretamente a educação infantil, ele representa um proxy da qualidade da educação existente no município.

${ }^{g}$ A categoria inadequada, segundo o IBGE, inclui os domicílios particulares permanentes com abastecimento de água proveniente de poço ou nascente ou outra forma, sem banheiro e sanitário ou com escoadouro ligado à fossa rudimentar, vala, rio, lagwo, mar ou outra forma e lixo queimado, enterrado ou jogado em terreno baldio ou logradouro, em rio, lago ou mar ou outro destino e mais de 2 moradores por dormitório.

${ }^{\mathrm{h}}$ Ambas as variáveis desse indicador foram utilizadas por Arretche e Marques (2002).

i "Escolinhas" são consideradas as escolas exclusivas de educação infantil.

${ }^{j}$ Foram considerados de esquerda (com valor 1 na variável dummy) as gestões que apresentaram um dos três partidos - PT, PDT, PSB - como partido do prefeito. Nenhum dos outros partidos classificados tradicionalmente como de esquerda estava à frente de prefeituras gaúchas nos períodos pesquisados. Essa indexação está de acordo com as análises de: Coppedge (1997) - para o PT e PSB, Arretche e Marques (2002), Carreirão e Kinzo (2004). Reflexão teórica sobre o uso do esquema esquerda-direita como síntese de orientações ideológicas pode ser encontrada em Mainwaring; Torcal (2005). 
Ainda quanto às variáveis independentes, em três delas os valores ausentes (missings) foram substituídos pela média dos valores conhecidos: "IDEB 4o ou 5으 ano - 2005", "Taxa das despesas pagas em educação 2006/população 2000", "\% das despesas com educação infantil nas despesas pagas em educação - 2006".

Quanto ao universo da pesquisa, iniciamos com os 496 municípios do RS considerados no Censo Demográfico de 2010. Desses, foram excluídos 29 que não continham informações censitárias relativas a 2000, restando, então, 467 municípios.

\section{Argumentos sobre a inclusão dos indicadores e respectivas variáveis nos modelos de regressão acerca das chances de adesão ao PROINFANCIA}

a) Aspectos demográficos - A participação da faixa etária dos 0 a 5 anos na população total e o percentual de crianças até cinco anos que residem em área rural podem influenciar a chance da prefeitura aderir, pois revelam a demanda latente, o quantum de vagas a ser contemplado. Aumentos populacionais identificados através da variação populacional de 2007 em relação a 2000 também pressionam a oferta, pois incidem, hipoteticamente, na demanda latente. Variáveis relacionadas com a urbanização dos municípios (taxa de urbanização e densidade demográfica) interferem na decisão de participar do PROINFANCIA, pois as cidades mais urbanizadas e densamente povoadas possuem maior demanda por escolas de educação infantil e mais investem nesses equipamentos.

b) Pertencimento à área metropolitana e influência externa - Supõe-se que municípios metropolitanose/ou com influência exterior à própria localidade (por exemplo, centros de zona e de regiões), possuam maior chance de aderirem ao PROINFANCIA devido à sua posição no contexto estadual e nacional, bem como à maior proximidade de centros econômicos, políticos e de instâncias governamentais de formulação de políticas públicas. Em sentido contrário, estima-se que tais municípios tenham mais recursos, e, por conta disso, acessem menos os programas federais.

c) Atividades econômicas principais - Conforme dados sobre oferta de escolas e de matrículas em educação infantil, os espaços rurais são os menos providos de creche e pré-escola, até porque o cuidado das crianças pequenas por vezes faz parte da própria dinâmica familiar. Não obstante, como já mencionado, as trabalhadoras rurais têm reivindicado creche para os seus filhos, fato que revela transformações ocorridas no campo, com a crescente participação feminina no trabalho e na vida social das localidades e a diluição das fronteiras 
entre o rural e o urbano, devido ao acesso às tecnologias de informação, à massificação dos hábitos de comportamento e de consumo, aos movimentos migratórios e deslocamentos pendulares diários dos que residem no campo e trabalham na cidade (BARBosA; GeHLEn; Fernandes, 2012). Por outro lado, municípios mais industrializados e com maior proporção de ocupados no comércio/reparação de veículos e nos serviços pressupõem a existência de maior demanda por equipamentos educacionais para atendimento dos filhos pequenos dos trabalhadores. Em resumo, se por um lado maiores índices de valor adicionado e de ocupação em atividades tradicionalmente urbanas indústria, comércio, serviços - evidenciam a presença de uma demanda latente por escolas de educação infantil, por outro as mudanças na organização e na dinâmica da agricultura familiar (com forte presença no $\mathrm{RS}^{11}$ ) podem estar provocando um alargamento dessa mesma demanda, assim pressionando a oferta pública de creches e pré-escolas, o que termina por impulsionar os municípios a buscarem recursos federais.

d) Riqueza e origem da renda - Municípios com maior PIB per capita e renda per capita e maior participação das rendas provenientes do trabalho ou de transferências governamentais contam com recursos próprios (receitas, tributos) para investir em serviços sociais, e supostamente não adiram ao PROINFANCIA.

e) Qualidade de vida e na educação - Municípios com melhor qualidade de vida e na educação (em geral) tendem a investir mais em políticas sociais e equipamentos educacionais, seja com recursos próprios, seja participando de ações federais; para tanto, buscam se inserir em programas como o PROINFANCIA.

f) Vulnerabilidade social - Municípios com maior incidência de crianças indigentes e morando em domicílios inadequados, com altos índices de mortalidade infantil e de chefes de domicílio sem instrução representam os candidatos preferenciais das políticas sociais federais; portanto, pelas estratégias de indução e de acompanhamento técnico do Governo Federal, estariam mais propensos a aderir ao PROINFANCIA. Ao mesmo tempo, outro fator seria a dependência, nesses municípios, de parcela considerável da população para com a educação pública.

\footnotetext{
${ }^{11}$ Segundo o Censo Agropecuário de 2006 (IBGE), no Rio Grande do Sul 84\% do total de estabelecimentos agropecuários e $57 \%$ da área ocupada eram de agricultura familiar, sendo os percentuais restantes representados pela agricultura não familiar. Em comparação com os demais estados brasileiros, o RS ocupava a 12a posição em número de estabelecimentos e a 1 ạ posição quanto à área ocupada pela agricultura familiar.
} 
g) Capacidade fiscal da prefeitura - Quanto maior a capacidade de gasto e de arrecadação tributária da prefeitura municipal, maior a disponibilidade de recursos financeiros próprios para investir na educação infantil, e menor a necessidade de recorrer ao financiamento federal.

h) Oferta educacional no município (em geral e de educação infantil) Quanto maior é a oferta de educação em geral ou infantil (habitantes por escola, frequência à escola e matrículas de crianças até cinco anos de idade, instituições de ensino com pré-escola e outras etapas de ensino ou escolas exclusivas de educação infantil, localizadas na área urbana e rural, proporção de professores de educação infantil), tanto através do provimento público (municipal, estadual ou federal) quanto do privado, melhor é a situação educacional no município, tornando desnecessária a procura pelo PROINFANCIA.

i) Estruturas municipais e investimento da prefeitura em educação em geral e infantil - A maior presença de estruturas municipais educacionais (sistema de ensino próprio, Plano, Fundo e Conselho Municipais de Educação), o maior volume de despesas municipais em educação geral e infantil, a maior quantidade de equipamentos educativos municipais (escolas com educação básica, escolas com educação infantil, escolas exclusivas de educação infantil) favorecem a adesão ao PROINFANCIA, porque sinalizam a prioridade dada pela prefeitura à educação (geral e infantil), e a influência do legado das políticas prévias para a continuidade dos investimentos, a melhoria das estruturas educacionais existentes, bem como para o acúmulo de conhecimento e expertise nessa área de políticas sociais.

j) Ideologia do partido do prefeito - A inclusão dessa variável - uma dummy onde o valor 1 indica que o partido foi classificado como de esquerda justifica-se pelas seguintes razões: a) a ideologia do partido influencia a produção de políticas públicas, pois supõe uma atenção privilegiada a certos setores que representam o seu eleitorado. Dessa forma, partidos situados no campo da esquerda, ao priorizarem os grupos mais pobres, tenderiam a favorecer um Estado maior e mais ativo, regulando os mercados e usando os gastos públicos para corrigir desigualdades, principalmente através de políticas sociais. Esse argumento é referido pelos economistas Arvate, Avelino e Lucinda (2008). E, b) as transferências e repasses de recursos federais não têm caráter redistributivo, servindo como canal político entre os poderes executivos dos três níveis governamentais, cujos representantes buscam expandir os recursos especialmente nos anos eleitorais. Nesse sentido, o volume das transferências tende a ser maior para os prefeitos de partidos pertencentes à coalizão eleitoral dos governadores e presidente. 
Esse argumento é defendido pelos economistas Vieira e Arvate (2008). Na linha dessas considerações, supõe-se que os municípios cujo partido do prefeito é do campo da esquerda recorram mais ao PROINFANCIA.

Tendo em conta tais argumentos que explicam a seleção das variáveis independentes, a seguir examinaremos os resultados da regressão logística sobre as chances de adesão do município ao PROINFANCIA, entre os anos 2007 e 2009.

\section{Resultados}

Primeiramente destacamos que os resultados do modelo foram estatisticamente significativos ao nível $p<=0,001$.

A Tabela 2 mostra que somente três variáveis apresentaram-se como estatisticamente significativas com relação à adesão no período 2007-2009. Dessas, a ideologia do partido do prefeito aumentou em 2,6 vezes as chances do município aderir ao PROINFANCIA.

Por sua vez, dois fatores diminuíram as chances de adesão: o percentual do valor adicionado proveniente da indústria, em 3\%, e a taxa de alfabetização das pessoas de 15 ou mais anos, em menos de $1 \%$.

Tabela 2 - Resumo do modelo de regressão logística com as variáveis estatisticamente significativas - chances de adesão entre 2007 e $2009^{12}$

\begin{tabular}{l|l|l}
\hline $\begin{array}{l}\text { Variáveis estatisticamente significativas quanto à adesão ao } \\
\text { PROINFANCIA 2007-2009 }\end{array}$ & Sig. & Exp (B) \\
\hline Ideologia do partido do prefeito na gestão 2009-2012 & 0,001 & 2,653 \\
\hline \% do valor adicionado proveniente da indústria - 2006 & 0,050 & 0,033 \\
\hline $\begin{array}{l}\text { Taxa de alfabetização das pessoas com 15 ou mais anos } \\
\text { - 20001 }\end{array}$ & 0,047 & 0,000 \\
\hline
\end{tabular}

Fonte: Regressão logística, software SPSS .

* O indicador é calculado com base nos dados do IBGE, que pergunta aos entrevistados maiores de 15 anos se sabem ler e escrever. A taxa de alfabetização, portanto, considera alfabetizadas as pessoas que declaram saber ler e escrever.

Nenhuma das variáveis dos seguintes indicadores relacionou-se com as chances de adesão ao PROINFANCIA: a) aspectos demográficos; b) pertencimento à Região Metropolitana de Porto Alegre ou com influência externa; c) riqueza e origem

\footnotetext{
${ }^{12}$ Só aparecem nessa tabela os resultados com $\mathrm{p}<=0,050$. Ver no Apêndice 1 o quadro com o modelo completo, que contempla todas as variáveis.
} 
da renda; d) qualidade de vida inclusive educação; e) vulnerabilidade social; f) capacidade fiscal da prefeitura; g) oferta educacional do município - em geral e educação infantil (rede pública e privada); h) estruturas municipais e investimento da prefeitura em educação (geral e infantil).

Dentre as variáveis não influentes, merecem destaque as que identificam a demanda latente (\% de participação de 0 a 5 anos, e \% desta faixa etária residente na área rural), e a oferta em educação infantil (quantidade de matriculados e frequência à escola de acordo com a etapa de ensino). Como os dados populacionais e a oferta de creches e pré-escolas apresentaram pouca variabilidade entre os municípios, eles acabaram não interferindo nas chances de aderir.

\section{Discussão}

O artigo analisou um momento específico da "macro implementação" (BERMAN, 2007) do Programa Nacional de Reestruturação e Aparelhagem da Rede Escolar Pública de Educação Infantil (PROINFANCIA), quando ocorre a transição entre o programa federal e a adoção de projetos pelos governos locais. Frente à grande demanda latente, ao insuficiente atendimento educacional das crianças de 0 a 5 anos e à forte indução federal (através de legislação, diretrizes pedagógicas, metas de expansão normatizadas, programas educacionais específicos) para a ampliação da oferta pública municipal em educação infantil, buscou-se conhecer quais os fatores que condicionaram a decisão das prefeituras municipais do Rio Grande do Sul por aderir ou não ao PROINFANCIA em 2007-2009, uma vez que até o final deste período 298 municípios não tinham aderido ao programa.

Os fatores contemplados incluíram características socioeconômicas, demográficas, institucionais, de demanda e de oferta em educação geral e infantil, e a posição ideológica do partido do prefeito por ocasião do encaminhamento da proposta ou início da vigência do convênio ou termo de compromisso entre FNDE/ MEC e prefeitura municipal.

Destacamos, na sequência, os principais resultados do modelo de regressão logística.

A única variável com proeminência no sentido de aumentar em quase três vezes as chances de adesão ao PROINFANCIA foi a ideologia do partido do prefeito na gestão 2009-2012, o que sugere uma resposta mais efetiva das prefeituras municipais situadas no campo da esquerda à indução federal, e lembrando que no período estudado o Governo Federal era de esquerda.

Com relação às variáveis que reduziram as chances de adesão, duas se sobressaíram: o valor adicionado da indústria (3\%) e a taxa de alfabetização 
de pessoas de 15 ou mais anos. A primeira indica que os municípios mais industrializados tiveram menos chances de aderir ao programa. Isso quer dizer que ser mais industrializado diminui as chances de aderir, e tal fato se explica porque tais municípios possuem equipamentos escolares suficientes para atender a demanda, o que não acontece nas áreas menos industrializadas e rurais. Essas áreas, conforme já salientado, passam por transformações econômicas, sociais e culturais que repercutem na elevação da demanda por creche e pré-escola para crianças de até cinco anos de idade. A segunda variável pouco influenciou efetivamente, em menos de $1 \%$, ainda que no sentido de diminuir as chances de adesão. Supõe-se que ela não meça diretamente qualidade de ensino, posto que é baseada em uma pergunta sobre se o indivíduo sabe ou não ler ou escrever.

O estudo demonstrou, ainda, que a quase totalidade das características municipais investigadas - perfil socioeconômico e demográfico, qualidade da educação, situação educacional, capacidade fiscal da Prefeitura, estruturas municipais e investimentos das prefeituras em educação geral e infantil (o legado das políticas prévias) - não interferiu nas chances de adesão ao PROINFANCIA entre os anos 2007 e 2009.

Como já sugerido pela literatura da área de políticas públicas (BERMAN, 2007; Arretche, 1999; Arretche; MARques, 2002; SouzA, 2004), as características dos municípios e de suas prefeituras explicam, em parte, a sua participação em programas federais. Outra parte da explicação, também salientada pelos autores, deve-se às regras e metas previstas na legislação vigente, à natureza da política, à estratégia de indução e aos incentivos propostos pela esfera governamental superior, bem como à aproximação entre os objetivos programáticos do Governo Federal e os interesses locais.

Nesse sentido, admitindo-se que a indução e os incentivos propiciados pela instância governamental superior importam para a adesão dos governos subnacionais às políticas federais, os resultados de pesquisa relativos ao PROINFANCIA no Rio Grande do Sul levam a crer que a estratégia federal foi mais eficaz em relação aos municípios cujas prefeituras eram administradas por partidos de mesmo espectro ideológico; e menos efetiva quanto aos municípios mais industrializados, já que se supõe que esses, por arrecadarem mais, conseguem investir o mínimo exigido legalmente para a área de educação. ${ }^{13}$

\footnotetext{
${ }^{13}$ Para testar se municípios mais industrializados tendem a ter governos mais de direita realizamos um teste t para diferenças de proporção, o qual nos mostrou que o percentual agregado proveniente da indústria é levemente maior nos municípios com prefeituras de orientação de direita (17\%) em comparação com aqueles de orientação de esquerda (15\%), sendo que o teste não demonstrou ser essa uma diferença estatisticamente significativa ao
} 


\section{Referências bibliográficas}

Abrucio, Fernando Luís; Franzese, Cibele. Federalismo e políticas públicas: o impacto das relações intergovernamentais no Brasil. 2011 Disponível em: <http:// www.defesasocial.rn.gov.br/contentproducao/aplicacao/searh_escola/arquivos/ pdf/paper-federalismo-fernando-abrucio.pdf.>Acesso em: 20 de janeiro.

ALMEIDA, Maria Hermínia Tavares de. Recentralizando a federação?. Revista de Sociologia e Política, Curitiba, n. 24, p. 29-40. 2005. (Dossiê Federalismo).

ALMEIDA, Marina. Corrida contra o Atraso: PAC2 prevê a construção de 6 mil novas unidades de educação infantil, com investimentos de $\mathrm{R} \$$ 7,6 bilhões. Revista Escola Pública (online), edição 33, abril, 2013. Disponível em: <http://revistaescolapublica. uol.com.br/textos/15/artigo246377-1.asp.> Acesso em: 24 de maio.

Arretche, Marta. Políticas sociais no Brasil: descentralização em um estado federativo. Revista Brasileira de Ciências Sociais, São Paulo, v. 14, n. 40, p. 111-141, 1999.

ARRETCHE, Marta; MARQUES, Eduardo. Municipalização da saúde no Brasil: diferenças regionais, poder do voto e estratégias de governo. Ciência e saúde coletiva, Rio de Janeiro, v. 7, n. 3, p. 455-479, 2002

ARRETCHE, Marta. Quem taxa e quem gasta: a barganha federativa na federação brasileira. Revista de Sociologia e Política, Curitiba, n. 24, p. 9-27, junho, 2005 (Dossiê Teoria Política).

ARvate, Paulo Roberto; Avelino, George; LUCINDA, Cláudio Ribeiro. Existe influência da ideologia sobre o resultado fiscal dos governos estaduais brasileiros? Estudos Econômicos, São Paulo, v. 38, n. 4, p. 789-814, out./dez, 2008.

BARBosA, Maria Carmen et al. Oferta e demanda de educação infantil no campo. Porto Alegre: Evangraf, 2012.

BarbosA, Maria Carmen; Gehlen, Ivaldo; Fernandes, Susana Beatriz. A oferta e a demanda de educação infantil no campo: um estudo a partir de dados primários. In: BARBoSA, Maria Carmen et al. Oferta e demanda de educação infantil no campo. Porto Alegre: Evangraf, p. 71-105, 2012.

BERMAN, Paul. El estudio de la macro y micro-implementación. In: VILLANUEVA, Luis F. Aguilar. La implementación de las políticas. México: Miguel Ángel Porrúa. p. 281317, 2007.

Blog do Planalto. Governo construirá 718 creches do PAC 2; outras 54 foram entregues. Brasília, 24/03/2011. Disponível em: <http://blog.planalto.gov.br/ governo-construira-718-creches-do-pac-2-outras-54-foram-entregues/2> Acesso em: 24 de maio de 2013.

BRASIL. Constituição da República Federativa do Brasil. Brasília. 1988.

nível $p<=0,05$. 
Emenda Constitucional no 59, de 11 de novembro de 2009.Disponível em: <http://www.planalto.gov.br/ccivil_03/constituicao/Emendas/Emc/emc59. htm> Acesso em: 20 de março de 2013.

Lei $n$ o 9394, de 20 de dezembro de 1996. Disponível em: <http:// www.planalto.gov.br/ccivil_03/LEIS/L9394.htm> Acesso em: 23 de julho de 2013.

. Lei no 10.172, de 09 de janeiro de 2001. 2001. Disponível em: <http:// www.planalto.gov.br/ccivil_03/LEIS/LEIS_2001/L10172.htm> Acesso em: 10 de julho de 2013.

Lei no 11.114, de 16 de maio de 2005. 2005. Brasília. Disponível em: <http://www.educandariorp.com.br/Legislacao/Lei-11114-05.pdf> Acesso em: 20 de julho de 2013.

Lei no 11.274. 2006. Disponível em: <http://presrepublica.jusbrasil. com.br/legislacao/96008/lei-11274-06> Acesso em: 22 de julho de 2013.

Lei $n$ o 11.494, de 20 de junho de 2007. 2007. Disponível em: <http:// www010.dataprev.gov.br/sislex/paginas/42/2007/11494.htm> Acesso em: 10 de julho de 2013.

Lei $n$ o 12.499, de 29 de setembro de 2011. Disponível em: <http:// presrepublica.jusbrasil.com.br/legislacao/1029345/lei-12499-11> Acesso em: 30 de julho de 2013.

Lei $n$ o 12.796, de 04 de abril de 2013. 2013.Disponível em: <http:// redebrasilia.com/lei-1279613-lei-no-12-796-de-4-de-abril-de-2013/> Acesso em: 21 de março de 2013.

Decreto $n$ o 2.264, de 27 de junho de 1997. Disponível em: http:// www.pedagogiaemfoco.pro.br/d2264_97.htm. Acesso em: 22 de julho de 2013.

Plano de Desenvolvimento da Educação. 2007. Disponível em: <http:// portal.mec.gov.br/arquivos/livro/index.htm> Acesso em: 10 de julho de 2013.

Projeto de lei no 8035, apresentado pelo Executivo à Câmara dos Deputados em 20 de dezembro de 2010. 2010. Disponível em: <http://www. camara.gov.br/proposicoesWeb/fichadetramitacao?idProposicao=490116> Acesso em: 10 de julho de 2013.

Sistema Integrado de Administração Financeira do Governo Federal (SIAFI). Disponível em: <http://www.portaldatransparencia.gov.br/> Acesso em: 21 de dezembro.

CARreIRÃo, Yan de Souza; Kınzo, Maria D’Alva G. Partidos políticos, preferência partidária e decisão eleitoral no Brasil (1989/2002). DADOS - Revista de Ciências Sociais, Rio de Janeiro, v. 47, n. 1, p. 131 a 168, 2004.

Conselho nacional de Educação. CÂmara de Educação Básica. Parecer $n$ o 01, de 07 de abril de 1999. 1999. Disponível em: <http://portal.mec.gov.br/cne/arquivos/ pdf/CEB0199.pdf> Acesso em: 10 de julho de 2013.

Parecer $n$ o 02, de 19 de abril de 1999. Disponível em: <http://www. klickeducacao.com.br/2006/arq_img_upload/anexo/184/CEB0299.pdf> Acesso em: 20 de julho de 2013. 
Parecer normativo no 4, de 16 de fevereiro de 2000. Disponível em: <http://www.crmariocovas.sp.gov.br/pdf/diretrizes_p0619-0628_c.pdf> Acesso em: 20 de julho de 2013.

Resolução no 5, de 17 de dezembro de 2009. 2009. Disponível em: <http://portal.mec.gov.br/index.php?option=com_content\&id=12992: diretrizespara-a-educacao-basica> Acesso em: 26 de julho de 2013.

Coppedge, Michael. A Classification of Latin American Political Parties. WorkingPaper \# 244. Kellogg Institute, November. 1997.

Instituto De Pesquisas Econômicas Aplicadas (IPEA). Políticas Sociais: acompanhamento e análise. Capítulo 4: Educação. Brasília, 2011, p. 129-164. Disponível em: <http://www.ipea.gov.br/portal/images/stories/PDFs/politicas_ sociais/bps_19_completo.pdf> Acesso em: 05 de março de 2013.

instituto nacional de Estudos E Pesquisas Educacionais anísio Teixeira (INEP). Proporção do investimento público em educação por nível de ensino (tabela). Brasília: s/d. Disponível em: <http://portal.inep.gov.br/web/guest/ estatisticas-gastoseducacao-indicadores_financeiros-p.i.p._nivel_ensino.htm> Acesso em: 26 de julho.

LONG, S.; FREESE, J. Regression Models for Categorical Dependent Variables. Stata Press, USA. 2006.

MaINWARING, Scott; TORCAL, Mariano. Teoria e institucionalização dos sistemas partidários após a terceira onda de democratização. Opinião Pública, Campinas, Vol. XI, no 2, Outubro, p. 249-286, 2005.

mec muda Critérios para fazer deslanchar Programa de Creches. Valor Econômico, São Paulo, 15 de março de 2011. 2011. Disponível em: <http://www. todospelaeducacao.org.br/comunicacao-e-midia/educacao-na-midia/14067/mecmuda-criterios-para-fazer-deslanchar-programa-de-creches> Acesso em: 30 de julho de 2013.

Melo, Marcus André. Crise federativa, guerra fiscal e "hobbesbianismo municipal": efeitos perversos da descentralização. São Paulo em Perspectiva, São Paulo, v. 10, n. 3, p. 11-22, jul./set. 1996.

PoWers, D; XIE, Y. Statistical Methods for Categorical Data Analysis. San Diego: Academic Press.2000.

RODDEN, Jonathan. Federalismo e descentralização em perspectiva comparada: sobre significados e medidas. Revista de Sociologia e Política, Curitiba, n. 24, p. 9-27. 2005.(Dossiê Federalismo)

Rosemberg, Fúlvia; ARTES, Amélia. O rural e o urbano na oferta de educação para crianças de até 6 anos. In: BARBOSA, Maria Carmen et al. Oferta e demanda de educação infantil no campo. Porto Alegre: Evangraf, 2012. p. 13-69.

SAVIANI, Demerval. O Plano de desenvolvimento da educação: análise do projeto do MEC. Educação e Sociedade, Campinas, vol. 28, n. 100 - Especial, p. 1231-1255, outubro, 2007.. Disponível em: <http://www.cedes.unicamp.br> Acesso em: 23 de julho. 
SouzA, Celina. Governos locais e gestão de políticas sociais universais. São Paulo em Perspectiva, São Paulo, v. 18, n. 2, p. 27-41, abr./jun. 2004.

Federalismo, desenho constitucional e instituições federativas no Brasil pós-1988. Revista de Sociologia e Política, Curitiba, n. 24, p. 105-121. 2005. (Dossiê Federalismo)

Vieira, Fausto J. A.; Arvate, Paulo Roberto. Eleições municipais: como interagem os prefeitos e as outras esferas de governo para alcançar maior sucesso nas urnas. Trabalho apresentado no XXXVI Encontro da Associação Nacional ac. dos Centros de Pós-Graduação em Economia. Salvador. 2008. Disponível em: <www.anpec. org.br/encontro2008/artigos/200807211138360-.pdf> Acesso em: 05 de agosto de 2013.

\section{Letícia Maria Schabbach}

Possui Doutorado em Sociologia (2007) pela Universidade Federal do Rio Grande do Sul (UFRGS). É professora adjunta IV do Departamento de Sociologia da UFRGS, atuando nos cursos de graduação de Ciências Sociais e de Políticas Públicas, no Programa de Pós-graduação em Sociologia e no Programa de Pós-graduação em Políticas Públicas. Coordena o Programa de Pós-graduação em Políticas Públicas da UFRGS, que abrange os cursos de Doutorado e Mestrado. Contato: leticiams65@gmail.com

\section{Marília Patta Ramos}

Possui doutorado em Sociologia - Purdue University, EUA. Concluiu seu pós doutoramento no Programa Vilmar Faria (PVF) de Análise Quantitativa em Políticas Públicas no Population Research Center (PRC) da Universidade do Texas, EUA. Atualmente é professora adjunta IV no departamento de Sociologia da UFRGS. É orientadora de mestrado e doutorado no PPG de Sociologia e de Políticas Públicas da UFRGS. Contato: mariliaramos68@gmail.com 
Apêndice 1

\begin{tabular}{|c|c|c|c|c|c|c|c|}
\hline & & \multicolumn{2}{|c|}{ Variables in the } & \multicolumn{4}{|l|}{ Equation } \\
\hline & & B & S.E. & Wald & $\mathrm{df}$ & Sig. & $\operatorname{Exp}(B)$ \\
\hline \multirow[t]{35}{*}{ Step $1^{\text {a }}$} & V1pop0a5 & 000 & ,000 & 1,565 & 1 & 211 & 1,000 \\
\hline & V2pop0a5_A & 10,346 & 14,221 & ,529 & 1 & ,467 & 31137,484 \\
\hline & V3pop0a5rural & $-2,042$ & 1,155 & 3,127 & 1 & ,077 & 130 \\
\hline & V4var_pop & $-2,943$ & 1,815 & 2,627 & 1 & 105 & ,053 \\
\hline & V5pop_urb &,- 033 & 102 & 103 & 1 & 748 & 968 \\
\hline & V7RMPA2006 & 156 & ,634 & ,060 & 1 & ,806 & 1,168 \\
\hline & V8influencia & 272 & ,375 & ,526 & 1 & ,468 & 1,313 \\
\hline & V9va_ind2006 & $-3,413$ & 1,739 & 3,853 & 1 & ,050 & ,033 \\
\hline & V10ocup_ind & 2,387 & 1,675 & 2,030 & 1 & 154 & 10,881 \\
\hline & V11va_serv2006 &,- 958 & 1,977 & ,235 & 1 & ,628 & 384 \\
\hline & V12ocup_comercio & 5,242 & 3,879 & 1,826 & 1 & 177 & 189,096 \\
\hline & V13area_agfam & ,503 & ,650 & ,598 & 1 & ,439 & 1,653 \\
\hline & V14PIBpercapitaR\$ & 000 & ,000 & 203 & 1 & ,652 & 1,000 \\
\hline & 2006 & & & & & & \\
\hline & V15renda_pc & 005 & ,003 & 2,644 & 1 & 104 & 1,005 \\
\hline & V16Rendadotrabalh & $-5,665$ & 4,111 & 1,899 & 1 & 168 & ,003 \\
\hline & 02000 & & & & & & \\
\hline & V17Rendadetransfe & 1,793 & 6,453 & ,077 & 1 & 781 & 6,006 \\
\hline & rênciasgovernamen & & & & & & \\
\hline & tais2000 & & & & & & \\
\hline & V18Idese2006 & $-1,340$ & 4,379 & ,094 & 1 & ,760 & ,262 \\
\hline & V19Domi_adeq &,- 451 & ,890 & ,257 & 1 & ,612 & 637 \\
\hline & V20alf2000 & 32,578 & 16,427 & 3,933 & 1 & ,047 & ,000 \\
\hline & V21IDEB2005_4ou & 213 & 319 & ,444 & 1 & ,505 & 1,237 \\
\hline & 5_1 & & & & & & \\
\hline & V22Ind_0a14 & ,580 & 2,405 & , 058 & 1 & 809 & 1,786 \\
\hline & V23crianca_inad &,- 309 & 2,137 & 021 & 1 & ,885 & 734 \\
\hline & V24Mortinf2006 & ,002 & ,007 & 116 & 1 & 733 & 1,002 \\
\hline & V25chefs_ins & ,856 & 4,302 & ,040 & 1 & ,842 & 2,354 \\
\hline & V26capacidadegass & ,000 & ,000 & ,367 & 1 & ,545 & 1,000 \\
\hline & to & & & & & & \\
\hline & V27receitatributáriar &,- 380 & 3,303 & ,013 & 1 & 908 & 684 \\
\hline & eceitascorrentes 200 & & & & & & \\
\hline & 6 & & & & & & \\
\hline & V28hab_esc & 001 & ,001 & ,883 & 1 & 347 & 1,001 \\
\hline
\end{tabular}




\begin{tabular}{|c|c|c|c|c|c|c|}
\hline V29freq0a5 & 1,781 & 1,876 & 901 & 1 & 342, & 5,938 \\
\hline V30atendimento0a5 & 2,187 & 2,311 & ,896 & 1 & 344 & 8,911 \\
\hline V31ProfEl_prof &,- 654 & 2,955 & ,049 & 1 & ,825 & ,520 \\
\hline $\begin{array}{l}\text { V32EscEl_outros_r } \\
\text { ur }\end{array}$ &,- 545 & ,505 & 1,162 & 1 & ,281 &, 580 \\
\hline V33El_transporte & $-1,075$ & 1,572 & ,468 & 1 & ,494 & ,341 \\
\hline V34Escolinha_El &,- 118 & ,695 & 029 & 1 & ,865 & 889 \\
\hline V35Escolinha_rur &,- 120 & 797 & 023 & 1 &, 880 & 887 \\
\hline V36Escolinha_par & ,311 & ,714 & 190 & 1 & ,663 & 1,365 \\
\hline $\begin{array}{l}\text { V37sistema_ed_pro } \\
\text { prio }\end{array}$ & 171 & ,247 & ,480 & 1 & ,488 & 1,187 \\
\hline V38planoeduc &,- 183 & ,340 & ,289 & 1 & ,591 & ,833 \\
\hline V39fundoeduc &,- 290 & ,294 & 969 & 1 & ,325 & ,748 \\
\hline V40conselhoeduc &,- 050 & ,509 & ,010 & 1 & ,922 & 951 \\
\hline $\begin{array}{l}\text { V41taxdesp_pop20 } \\
00 \_1\end{array}$ & ,000 & ,001 & 121 & 1 & ,728 & 1,000 \\
\hline V42Esc_mun & ,312 & 1,004 & ,096 & 1 & ,756 & 1,365 \\
\hline V43despEl_1 & $-1,204$ & 1,810 & ,442 & 1 & ,506 & ,300 \\
\hline $\begin{array}{l}\text { V44EscEI_munNO } \\
\text { VA }\end{array}$ &,- 064 & ,636 & ,010 & 1 & ,920 & ,938 \\
\hline V45Escolinha_mun & ,295 & ,491 & 360 & 1 & ,548 & 1,343 \\
\hline V46ideol2005_2008 &,- 038 & ,283 & ,018 & 1 & ,892 & 962 \\
\hline V47ideol2009_2012 & ,976 & ,285 & 11,724 & 1 & ,001 & 2,653 \\
\hline $\begin{array}{l}\text { V6dens2000_coline } \\
\text { ar }\end{array}$ &, 000 & ,001 & 152 & 1 & ,696 & 1,000 \\
\hline Constant & 28,954 & 16,466 & 3,092 & 1 & ,079 & $3,755 \mathrm{E} 12$ \\
\hline
\end{tabular}

a.Variable(s) entered on step 1:V1pop0a5, V2pop0a5_A, V3pop0a5rural, V4var_pop, V5pop_urb, V7RMPA2006, V8influencia, V9va_ind2006, V10ocup_ind, V11va_serv2006, V12ocup_comercio, V13area_agfam, V14PIBpercapitaR\$2006, V15renda_pc, V16Rendadotrabalho2000, V17Rendadetransferênciasgoverna mentais2000, V18Idese2006, V19Domi_adeq, V20alf2000, V21IDEB2005_4ou5_1, V22Ind_0a14, V23crianca_inad, V24Mortinf2006, V25chefs_ins, V26capacidadegassto, V27receitatributáriareceitascorrentes2006, V28hab_esc, V29freq0a5, V30atendimento0a5, V31ProfEI_prof, V32EscEI_outros_rur, V33EI_transporte, V34Escolinha_EI, V35Escolinha_rur, V36Escolinha_par, V37sistema_ed_proprio, V38planoeduc, V39fundoeduc, V40conselhoeduc, V41taxdesp_pop2000_1, V42Esc_mun, V43despEI_1, V44EscEI_munNOVA, V45Escolinha_mun, V46ideol2005_ 2008, V47ideol2009_2012, V6dens2000_colinear. 